\title{
Neck circumference measurement as a screening tool for obesity in children - A cross sectional study
}

\author{
Umayorubhagom Ashok, SulakshanaS. Baliga *, Padmaja R. Walvekar \\ Department of Community Medicine, Jawaharlal Nehru Medical College, Belagavi, Karnataka, 590010, India
}

\section{A R T I C L E I N F O}

\section{Keywords:}

Children

Obesity

Body mass index

Neck circumference

\begin{abstract}
A B S T R A C T
Background: Conventional anthropometric measurements for obesity in children offer several limitations which the newer methods propose to overcome.

Objective: To determine whether neck circumference can be used as a screening tool to identify obesity in children and to find out the correlation between neck circumference and body mass index, waist circumference, waist/hip ratio in evaluation of obesity in children.

Methodology: This was a cross-sectional study. Total 360 children (13-16 years) of a private school were study participants. Body mass index, waist circumference, hip circumference, waist-to hip ratio was compared with neck circumference of the same subjects. Pearson's correlation coefficient was calculated between neck circumference and other obesity indices. Data was analyzed and compared using $t$-test/ANOVA and the significance level was set at $\mathrm{p}<0.05$.

Result: The mean weight, waist circumference, neck circumference, hip circumference was significantly less in the group with Body mass index less than $23 \mathrm{~kg} / \mathrm{m}^{2}$ in comparison to the subjects with Body mass index greater than or equal $23 \mathrm{~kg} / \mathrm{m}^{2}$ ( $p$ value $<0.0001$ ) for both the sexes. Ratio of males was more than females and the mean \pm Standard Deviation of Body mass index was $20.88 \pm 3.9 \mathrm{~kg} / \mathrm{m}^{2}$ with prevalence of obesity $25.56 \%$. Conclusion: The neck circumference is an efficacious tool for screening obesity with good sensitivity and specificity. There was a significant correlation between neck Circumference and different anthropometric measurement in both the sexes.
\end{abstract}

\section{Introduction}

Obesity and overweight can lead to a range of chronic noncommunicable diseases, such as cardiovascular disease, metabolic syndrome, and diabetes mellitus etc. ${ }^{1}$ Obesity in young age is a growing chief public health crisis, particularly hazardous for type 2 diabetes mellitus, hypertension, and cardiovascular disorders in the later stages of life. In children, the prevalence of obesity has increased up to $300 \%$ over the last 40 years. ${ }^{2}$ The National Health and Nutrition Examination Survey (2009-2010) found 32\% of children between 2 and 19 years of age to be overweight or obese. ${ }^{2}$ Obesity varied from 10 to $40 \%$ in different European populations. ${ }^{3}$ Upper body trunk girth is an important predictor of obesity related complications such as hypertension, diabetes and cardiovascular diseases. ${ }^{2}$

Currently various methods have been used to assess obesity in children like BMI and waist hip ratio. But each of them has limitations. BMI is widely used tool to define obesity in children as well as adults but is actually an inaccurate and misleading indicator as it is suboptimal to assess the total body fat and central obesity. Waist circumference is not only time consuming but also problematic in terms of cultural and environmental issues. Also, WC may be affected by abdominal distention after consuming meals. ${ }^{3,4}$ Thus, these are broad and non-specific tools. So, there is a need of alternative tools to assess obesity in children as prevention of childhood obesity can prevent non communicable diseases in adulthood.

Neck circumference (NC), an indicator of upper body subcutaneous adipose tissue allocation can predict a higher metabolic threat. ${ }^{1,2}$ Neck circumference is correlated with cardiovascular disease risk factors even after adjustment for visceral adipose tissue (VAT) and BMI. These findings indicate that upper body fat may be a distinctive, pathogenic fat store. ${ }^{5}$ Neck circumference measurement is a distinct anthropometric dimension compared to body mass index, waist circumference,

\footnotetext{
* Corresponding author. Department of Community Medicine, Jawaharlal Nehru Medical College, KLE Academy of Higher Education and Research Nehru NagarBelagavi, Karnataka, 590010, India.

E-mail address: baliga1983@rediffmail.com (SulakshanaS. Baliga).
} 
waist/hip ratio and waist height ratio ${ }^{1,6}$ Significant advantage of the NC measurement in an assessment of overweight and obesity which is evaluated on a more secure body area when compared to WC. An added advantage of using $\mathrm{NC}$ as a proxy for upper body fat distribution is that it shows no variation in size throughout the day. ${ }^{1,10}$ The scientific literature on the accuracy of neck circumference (NC) as a tool to identify overweight and obesity is especially scarce, mainly in the children. Hence the present study aimed to determine the validity of neck circumference as a screening tool for obesity in children. The main objectives of the study were to determine whether neck circumference can be used as a screening tool to identify obesity in children and to find out the correlation between neck circumference and body mass index, waist circumference, waist/hip ratio in evaluation of obesity in children.

\section{Materials and methods}

The present Cross-sectional study was conducted in one of the private schools of Belagavi for 2 months on 360 children, studying in Class 8 th to 10 th in an urban school in Belagavi.

Universal sampling was carried out and all the students present on the data collection days were included in the study i.e., 360 students. School children aged between 13 and 16 years were included in the study while Children having goitre, cervical lymph adenopathy, neck masses, neck deformity, diabetes, Cushing's disease, and children on medication (steroid) were excluded. Data collector was trained in data collection and measurements.

Data was collected by the Principal investigator using weighing machine, height measuring scale and flexible measuring tape. Height was measured by using a stadiometer, each participant was instructed to stand barefoot and head held in Frankfurt horizontal plane to the nearest $0.1 \mathrm{~cm}$. Weight was measured by using a calibrated electronic weighing scale, to the nearest $0.1 \mathrm{~kg}$. Neck circumference was measured between the mid cervical spine and mid anterior neck, using a flexible measuring tape with the child in the standing position, head held erect and eyes facing forwards and neck in the horizontal plane at the level of most prominent position, the thyroid cartilage.

WC was measured by using flexible measuring tape to the nearest $0.1 \mathrm{~cm}$ with the child standing, and at the end of normal expiration at a point midway between the inferior margin of the lowest rib and the iliac crest.

Hip circumference was measured at the maximum circumference around the buttocks.

Waist-To-Hip Ratio (WHR) was calculated by dividing WC by HC.

BMI $\mathrm{kg} / \mathrm{m}^{2}$ was calculated and interpreted according to WHO guidelines using formula Weight in kilograms $(\mathrm{kg}) /$ (Height in meter). BMI for age and sex percentile growth curves were used to classify the subjects and was defined as Underweight (Less than 5th percentile), Normal weight (5th percentile to less than the 85th percentile), Overweight (85th to less than the 95th percentile) and Obese (Equal to or greater than the 95th percentile). Study subjects were divided into two categories based on BMI. One group with BMI less than $23 \mathrm{~kg} / \mathrm{m}^{2}$ and another group with BMI more than or equal to $23 \mathrm{~kg} / \mathrm{m}^{2}$.

Informed consent was obtained from the head of the school and assent was obtained from school students. Informed consent was also taken from parents. Approval was obtained from the Institutional Ethics committee before instating the study.

\subsection{Statistical analysis}

Data was analyzed using R software version 3.6.1 and Excel. Categorical variables were represented in the form of frequency table. Continuous variables were represented as mean \pm Standard Deviation (SD). Data was compared using $t$-test/ANOVA, Welch's $t$-test and MannWhitney test and the level of significance was set at $\mathrm{p}<0.05$.

\section{Results}

The present study recruited 360 participants between 13 and 16 years. Among the 360 subjects, 196 were males and the mean age observed was $14.38 \pm 0.85$ years and 164 were females. 92 subjects were identified with a BMI greater than $23 \mathrm{Kg} / \mathrm{m}^{2}$. Prevalence of obesity was $25.56 \%$.

Table 1 shows the distribution of age, neck circumference, waist circumference between the two groups and sexes. In males, mean weight, waist circumference, neck circumference, hip circumference was significantly less in the group with BMI less than $23 \mathrm{~kg} / \mathrm{m}^{2}$ compared to the subjects with BMI greater than or equal $23 \mathrm{~kg} / \mathrm{m}^{2}$ (pvalue $<0.05$ ). In females, mean weight, height, waist circumference, neck circumference, hip circumference was significantly less in the group with BMI less than $23 \mathrm{~kg} / \mathrm{m}^{2}$ compared to the subjects with BMI greater than or equal $23 \mathrm{~kg} / \mathrm{m}^{2}$. All the anthropometric parameters were found to be significantly higher in overweight/obese children than their normal weight peers and higher in boys when compared to girls.

Table 2 illustrates the sensitivity, specificity, area under curve, cutoff values, positive and negative likelihood ratio for neck circumference, waist circumference and hip circumference among males and females. In males, area under the curve for neck circumference assessing obesity was 0.7356 . A male patient was 4.05 times more likely to be obese if his neck circumference was greater than or equal to $32.5 \mathrm{~cm}$ (cut-off value). In females, area under the curve for neck circumference assessing obesity was 0.8178 . A female subject was 6.07 times more likely to be obese if her neck circumference was more than or equal to $30.5 \mathrm{~cm}$ (cut-off value). Total prevalence of obese male and female subjects was $32.65 \%$ and $22.96 \%$ and $28.06 \%$ and $23.97 \%$ with respect to neck circumference and BMI, respectively.

Fig. 1 illustrates the Receiver Operating Characteristic (ROC) curve of neck circumference to screen obesity in males and females.

Table 3 presents the correlation between BMI and other variables over gender. In males, a strong positive correlation was present between neck circumference and age, weight, waist circumference, hip circumference and BMI by Pearson correlation test. By Spearman's correlation test, there was a small amount of positive correlation between neck circumference and age. In females, a strong positive correlation was present between neck circumference and weight, waist circumference, hip circumference and BMI by Pearson correlation test.

Table 4 presents the sensitivity and specificity analysis for neck circumference over age. In males, $100 \%$ sensitivity in age group of 16 years with the cut-off value for NC of $32.5 \mathrm{~cm}$ was reported. In females, $86 \%$ sensitivity was observed with the cut-off value for $\mathrm{NC}$ as $30.5 \mathrm{~cm}$ in the age group of 15 years.

Table 5 depicts a significant association between BMI and neck circumference for males by Chi-square test.

Table 1

Baseline characteristics of study participants.

\begin{tabular}{lllll}
\hline \multirow{2}{*}{ Gender } & Variables & \multicolumn{2}{l}{ BMI $\left(\mathrm{kg} / \mathrm{m}^{2}\right)$} & \multirow{2}{*}{$\mathrm{p}$-value } \\
\cline { 3 - 4 } & & $<23 \mathrm{~kg} / \mathrm{m}^{2}$ & $\geq 23 \mathrm{~kg} / \mathrm{m}^{2}$ & \\
\hline \multirow{2}{*}{ Male } & Age & $14.35 \pm 0.8$ & $14.5 \pm 0.91$ & $0.4931^{\mathrm{M}}$ \\
& Weight (in kg) & $50.59 \pm 7.66$ & $71.52 \pm 12.74$ & $<0.00001^{\mathrm{wt}}$ \\
& Height (in cm) & $163.73 \pm 9.62$ & $165.74 \pm 9.48$ & $0.2134^{\mathrm{t}}$ \\
& Waist circumference & $72.94 \pm 6.97$ & $90.02 \pm 9.06$ & $<0.00001^{\mathrm{wt}}$ \\
& Neck circumference & $31.09 \pm 2.51$ & $34.07 \pm 1.99$ & $<0.00001^{\mathrm{t}}$ \\
& Hip circumference & $85.59 \pm 6.27$ & $101.76 \pm 8.01$ & $<0.00001^{\mathrm{t}}$ \\
& Age & $14.34 \pm 0.84$ & $14.4 \pm 0.89$ & $0.9571^{\mathrm{M}}$ \\
& Height (in cm) & $156.95 \pm 6.01$ & $159.15 \pm 5.76$ & $0.01629^{\mathrm{t}}$ \\
& Weight (in cm) & $47.45 \pm 6.25$ & $66.42 \pm 8.84$ & $<0.00001^{\mathrm{wt}}$ \\
& Waist circumference & $68.9 \pm 6.16$ & $82.33 \pm 8.14$ & $<0.00001^{\mathrm{t}}$ \\
& Neck circumference & $29.51 \pm 5.04$ & $31.67 \pm 1.97$ & $0.002313^{\mathrm{t}}$ \\
& Hip circumference & $86.72 \pm 5.44$ & $100.42 \pm 7.1$ & $<0.00001^{\mathrm{t}}$ \\
\hline
\end{tabular}

Abbreviations: t: $t$-test, Wt: Welch's $t$-test, M: Mann-Whitney test. *Significant pvalue $<0.05$. 
Table 2

Sensitivity and specificity analysis for neck, hip, and waist circumference over gender.

\begin{tabular}{|c|c|c|c|c|c|c|c|}
\hline Gender & Variables & Sensitivity (CI) & Specificity (CI) & AUC (CI) & Cut-off & $\mathrm{LR}^{+}(\mathrm{CI})$ & $\mathrm{LR}^{-}(\mathrm{CI})$ \\
\hline \multirow[t]{3}{*}{ Male } & Neck Circumference & $78 \%(63 \%-89 \%)$ & $81 \%(74 \%-87 \%)$ & $0.7356(0.6701-0.8011)$ & $32.5 \mathrm{~cm}$ & $4.05(2.82-5.82)$ & $0.28(0.16-0.48)$ \\
\hline & Waist Circumference & $82 \%(68 \%-92 \%)$ & $91 \%(86 \%-95 \%)$ & $0.8426(0.7785-0.9067)$ & $81.5 \mathrm{~cm}$ & 9.55 (5.58-16.34) & $0.19(0.10-0.37)$ \\
\hline & Hip Circumference & $87 \%(73 \%-95 \%)$ & $89 \%(83 \%-94 \%)$ & $0.8333(0.7704-0.8961)$ & $93.5 \mathrm{~cm}$ & $8.18(5.07-13.18)$ & $0.15(0.07-0.31)$ \\
\hline \multirow[t]{3}{*}{ Female } & Neck Circumference & $83 \%(69 \%-92 \%)$ & $86 \%(79 \%-92 \%)$ & $0.8178(0.7525-0.8832)$ & $30.5 \mathrm{~cm}$ & $6.07(3.78-9.74)$ & $0.20(0.10-0.37)$ \\
\hline & Waist Circumference & $89 \%(77 \%-96 \%)$ & $83 \%(75 \%-89 \%)$ & $0.8142(0.7519-0.8765)$ & $74.5 \mathrm{~cm}$ & $5.23(3.47-7.89)$ & $0.13(0.06-0.30)$ \\
\hline & Hip Circumference & $94 \%(82 \%-99 \%)$ & $88 \%(81 \%-93 \%)$ & $0.8652(0.7519-0.8765)$ & $92.5 \mathrm{~cm}$ & $7.82(4.76-12.86)$ & $0.07(0.02-0.22)$ \\
\hline
\end{tabular}

Abbreviations: AUC: Area Under Curve; $\mathrm{LR}^{+}$: Positive likelihood ratio; LR ${ }^{-}$: Negative likelihood ratio; CI: Confidence interval.
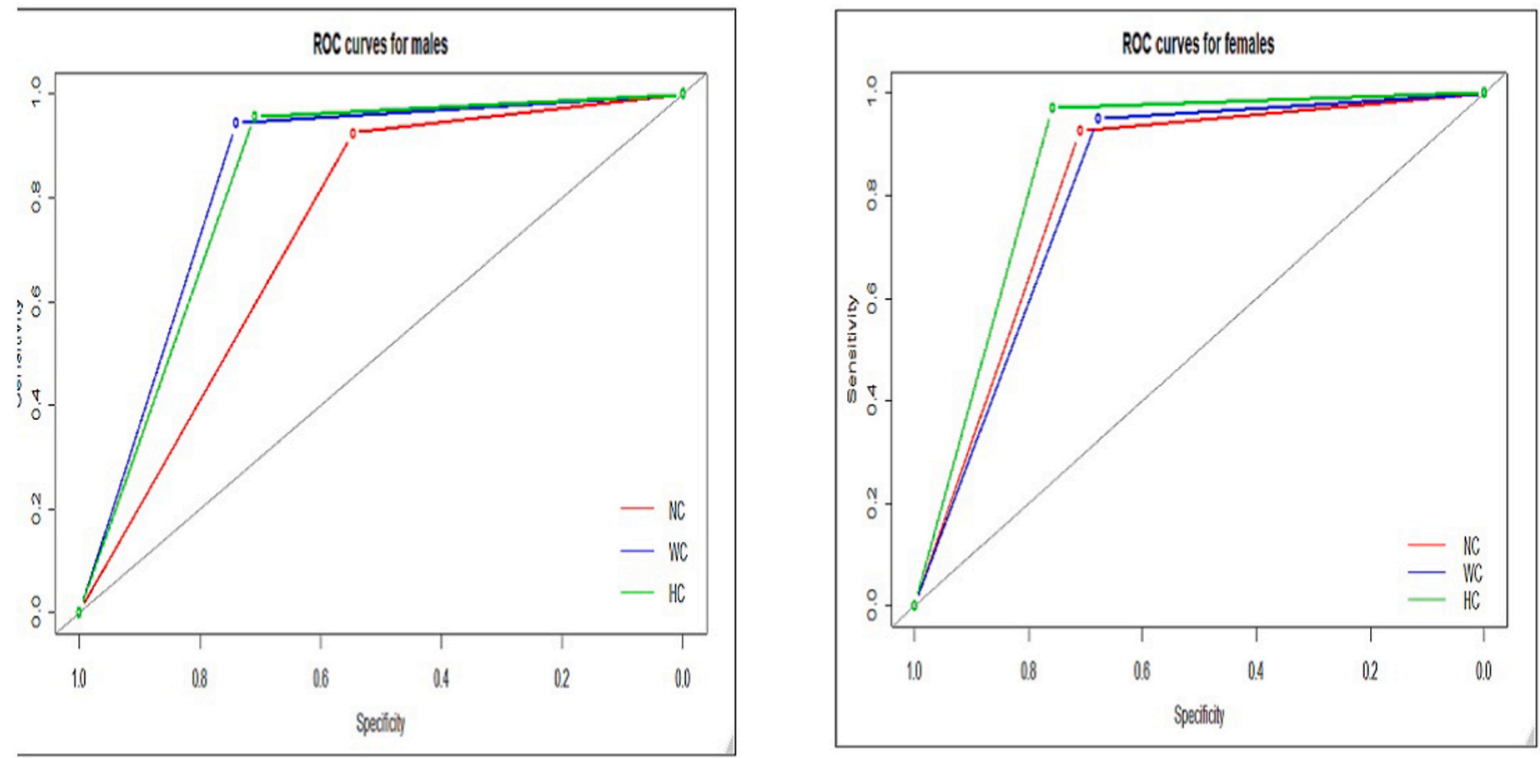

Fig. 1. ROC Curve for males and females to screen the obesity.

Table 3

Correlation analysis between neck circumference and other variables over gender.

\begin{tabular}{llll}
\hline Gender & Variables & Correlation coefficient & p-value \\
\hline Male & Age & 0.396941 (Spearman's rho) & $<0.0001$ \\
& Weight (in kg) & 0.8271033 & $<0.0001$ \\
& Waist circumference & 0.7213742 & $<0.0001$ \\
& Hip circumference & 0.8161293 & $<0.0001$ \\
& BMI $\left(\mathrm{kg} / \mathrm{m}^{2}\right)$ & 0.6775628 & $<0.0001$ \\
Female & Age & 0.072409 (Spearman's rho) & 0.3568 \\
& Weight (in $\mathrm{kg}$ ) & 0.742741 & $<0.0001$ \\
& Waist circumference & 0.67800 & $<0.0001$ \\
& Hip circumference & 0.676661 & $<0.0001$ \\
& BMI $\left(\mathrm{kg} / \mathrm{m}^{2}\right)$ & 0.662298 & $<0.0001$ \\
\hline
\end{tabular}

*Significant p-value $<0.05$.

\section{Discussion}

Before the 20th century, obesity was rare; but in 1997 World Health Organization (WHO) officially acknowledged obesity as a global epidemic. ${ }^{7}$ According to the WHO report, $65 \%$ of the world's population

Table 5

Comparison of neck circumference and BMI over gender.

\begin{tabular}{|c|c|c|c|c|c|}
\hline & & \multicolumn{2}{|l|}{ Male } & \multicolumn{2}{|l|}{ Female } \\
\hline & & $\mathrm{NC}<37$ & $\mathrm{NC} \geq 37$ & $\mathrm{NC}<37$ & $\mathrm{NC} \geq 37$ \\
\hline BMI $\left(\mathrm{kg} / \mathrm{m}^{2}\right)$ & $<23$ & 149 (99.33) & $1(0.67)$ & 115 (99.14) & $1(0.86)$ \\
\hline $\mathrm{p}$-value & $\geq 23$ & $\begin{array}{l}41(89.13) \\
0.00199^{\mathrm{MC} *}\end{array}$ & 5 (10.87) & $\begin{array}{l}47(97.92) \\
1^{\mathrm{MC}}\end{array}$ & $1(2.08)$ \\
\hline
\end{tabular}

MC: Monte-Carlo's simulation was used to obtain p-value; BMI: Body mass index, NC: neck circumference, *: Significant p-value $<0.05$.

Table 4

Sensitivity and specificity analysis for neck circumference over age.

\begin{tabular}{|c|c|c|c|c|c|c|}
\hline Gender & Age (in years) & Neck circumference (Mean $\pm \mathrm{SD}$ ) $\mathrm{kg} / \mathrm{m}^{2}$ & Sensitivity (CI) & Specificity (CI) & AUC (CI) & Cut-off $(\mathrm{cm})$ \\
\hline \multirow[t]{4}{*}{ Males } & 13 & $30.07 \pm 2.02$ & $67 \%(22 \%-96 \%)$ & $95 \%(77 \%-100 \%)$ & $0.8565(0.6519-1)$ & 31.5 \\
\hline & 14 & $31.57 \pm 3.24$ & $76 \%(50 \%-93 \%)$ & $83 \%(71 \%-91 \%)$ & $0.7357(0.6286-0.8429)$ & 32.5 \\
\hline & 15 & $32.42 \pm 2.09$ & $80 \%(52 \%-96 \%)$ & $71 \%(58 \%-83 \%)$ & $0.6794(0.5784-0.7804)$ & 32.5 \\
\hline & 16 & $32.93 \pm 1.53$ & $100 \%(54 \%-100 \%)$ & $78 \%(40 \%-97 \%)$ & $0.875(0.7146-1)$ & 32.5 \\
\hline \multirow[t]{4}{*}{ Females } & 13 & $29.07 \pm 2.07$ & $71 \%(29 \%-96 \%)$ & $91 \%(71 \%-99 \%)$ & $0.8117(0.6208-1)$ & 30.5 \\
\hline & 14 & $31.24 \pm 6.94$ & $85 \%(62 \%-97 \%)$ & $76 \%(60 \%-89 \%)$ & $0.78(0.6736-0.8865)$ & 30.5 \\
\hline & 15 & $29.45 \pm 1.76$ & $86 \%(57 \%-98 \%)$ & $92 \%(81 \%-98 \%)$ & $0.855(0.7421-0.9679)$ & 30.5 \\
\hline & 16 & $31.27 \pm 2.2$ & $83 \%(36 \%-100 \%)$ & $80 \%(28 \%-99 \%)$ & $0.8167(0.5615-1)$ & 30.5 \\
\hline
\end{tabular}

Abbreviations: AUC: Area Under Curve; CI: Confidence interval. 
live in countries where overweight and obesity kill more people than underweight. $^{8}$

The prevalence of obesity is growing at an alarming speed, and the harmful implications are renowned. The Waist hip ratio which is commonly used is usually known to recognize individuals with central obesity and overweight/obesity. ${ }^{6}$ But the limitation is waist circumference is less specific and can vary throughout the day in the postprandial period, in menstrual period, and according to bowel function. ${ }^{9}$

Neck circumference reflects the deposits of adipose tissue in the neck, which can be used as an indicator of subcutaneous adipose tissue in the upper body. The neck is at the junction between the head and the trunk, and is often not covered by clothing, which provides easy access for measurement. ${ }^{9}$ Similarly, NC measurements are less invasive than measuring WC and less cumbersome than assessing BMI. ${ }^{8}$

In present study, the observed ratio of males was more than females. The mean \pm Standard Deviation of BMI was $20.88 \pm 3.9 \mathrm{~kg} / \mathrm{m}^{2}$, and prevalence of obesity was $25.56 \%$.

A study conducted by Ferretti R de L et al. in children between adolescents showed that there was a significant correlation between neck circumference and body mass index in both the genders, (31.62 \pm 4.54 $\left.\mathrm{kg} / \mathrm{m}^{2}, \mathrm{p}<0.001\right) .{ }^{10}$ Similar findings were observed by Yashoda et al. (2017), (25.27 $\pm 2.0 \mathrm{~kg} / \mathrm{m}^{2}$, (p < 0.001)), Rajagopalan et al. (2017), $\left(18.81 \pm 0.2 \mathrm{~kg} / \mathrm{m}^{2}, \mathrm{p}<0.001\right)$ Kelishadi et al. (2016), $(31.35 \pm 0.7$, $\left.\mathrm{kg} / \mathrm{m}^{2} \mathrm{p}<0.01\right){ }^{2,11,12}$ Earlier Atef et al. (2015) $\left(28.98 \pm 1.6 \mathrm{~kg} / \mathrm{m}^{2}, \mathrm{p}<\right.$ 0.01 ), Hassan et al. (2015), (32.90 $\left.\pm 1.6 \mathrm{~kg} / \mathrm{m}^{2}, \mathrm{p}<0.01\right)$, Kim et al. (2014), ( $(\mathrm{r}=0.78, \mathrm{p}<0.001)$, Hatipoglu et al. (2010), $\left(28.0 \pm 0 \mathrm{~kg} / \mathrm{m}^{2}, \mathrm{p}\right.$ $<0.01)$, also showed a similar outcome in various age groups between 6 and 18 years. ${ }^{11-16}$

Numerous studies have reported the use of NC as a screening tool for the identification of obesity (high BMI), but the studies done in school children are limited. In the present study, mean weight, WC, NC, HC in males were observed significantly less in the group having less BMI than $23 \mathrm{~kg} / \mathrm{m}^{2}$ and in females, it was seen to have high or equal BMI after comparison. After comparison between the genders, females were 6.07 times more likely to be obese with NC of more or equal to $30.5 \mathrm{~cm}$. Finally, it was observed that AUC was more for WC, HC when compared to NC in boys and girl's ratio. In males, $100 \%$ sensitivity in age group of 16 years with the cut-off value for NC of $32.5 \mathrm{~cm}$ and in females, $86 \%$ sensitivity was observed with the cut-off value for NC as $30.5 \mathrm{~cm}$ in the age group of 15 years was reported. Thus, the study confirmed the utility of NC to assess obesity among the children.

The study had some limitations, that is it was a cross-sectional study with a small sample size in a single geographic area. Although neck circumference had a strong correlation with various obesity parameters there is a need to derive and validate neck circumference cut-off values for different pubertal stages, different BMI categories and different age groups for the Indian population.

\subsection{What is already known?}

Currently various methods have been used to assess obesity in children like BMI and waist hip ratio. But each of them has limitations.

\subsection{What this study adds?}

The present study concluded that NC is a valuable tool for screening the obesity among children (13yrs-16yrs) with reasonable sensitivity and specificity. It also established the obesity predictor cut-off values for this populace. There was a strong positive correlation between neck circumference and weight, BMI, hip circumference, waist circumference in both the genders.

\section{Funding}

None.

\section{Declaration of competing interest}

None declared.

\section{References}

1 Pei X, Liu L, Imam MU, et al. Neck circumference may be a valuable tool for screening individuals with obesity: findings from a young Chinese population and a meta-analysis. BMC Publ Health. 2018;18:529.

2 Yashoda HT, Swetha B, Goutham AS. Neck circumference measurement as a screening tool for obesity in children. Int J Contemp Pediatrics. 2017;4:426-430.

3 Lobstein T, Frelut ML. Prevalence of overweight among children in Europe. Obes Rev. 2003;4:196-200.

4 Nafiu OO, Burke C, Lee J, Voepel-Lewis T, Malviya S, Tremper KK. Neck circumference as a screening measure for identifying children with high body mass index. Pediatrics. 2010;126:e306-e310.

5 Morais AA, Morais UAB, Soares MMS, Romano MCC, Lamounier JA. Neck circumference in adolescents and cardiometabolic risk: a systematic review. Rev Assoc Med Bras. 2018;64:54-62.

6 Haslam D. Obesity: a medical history. Obes Rev. 2007;8:31-36.

7 Verma M, Rajput M, Sahoo SS, Kaur N. Neck circumference: independent predictor for overweight and obesity in adult population. Indian J Community Med. 2017;42: 209-213.

8 Zhang YL, Huo YN, Xu FH, et al. The relationship between neck circumference and central obesity in middle-aged and elderly community people of Nanchang. Chin $J$ Intern Med. 2015;54:725-726.

9 Song $\mathrm{Y}, \mathrm{Ma} \mathrm{J}$, Wang $\mathrm{H}-\mathrm{J}$, et al. Secular trends of obesity prevalence in Chinese children from 1985 to 2010: urban-rural disparity. Obesity. 2015;23:448-453.

10 Ferretti R de L, Cintra Ide P, Passos MA, de Moraes Ferrari GL, Fisberg M. Elevated neck circumference and associated factors in adolescents. BMC Publ Health. 2015;15: 208-210.

11 Rajagopalan A, Balaji N. Association of neck circumference and obesity with blood pressure among adolescents in urban and rural population in North Tamil Nadu. J Nat Sci Biol Med. 2017:8:144-147.

12 Kelishadi R, Djalalinia S, Motlagh ME, et al. Association of neck circumference with general and abdominal obesity in children and adolescents: the weight disorders survey of the CASPIAN-IV study. BMJ Open. 2016;6, e011794.

13 Atef A, Ibrahim A, Hassan NE, Elmasry SA, Elashry GI. Neck circumference as a novel screening method for estimating fat distribution and metabolic complications in obese children. Gaz Egypt Paediatr Assoc. 2015;63:91-97.

14 Hassan NE, Atef A, El-Masry SA, et al. Neck circumference as a predictor of adiposity among healthy and obese children. Open Access Maced J Med Sci. 2015;3:558-562.

15 Kim Y, Lee J-M, Laurson K, Bai Y, Gaesser GA, Welk GJ. Accuracy of neck circumference in classifying overweight and obese US children. ISRN Obes. 2014: 781841.

16 Hatipoglu N, Mazicioglu MM, Kurtoglu S, Kendirci M. Neck circumference: an additional tool of screening overweight and obesity in childhood. Eur J Pediatr. 2010; 169:733-739. 